NOTAS

\title{
TÉNEK Y NGIGUA: DOS EXPERIENCIAS
}

\section{Eva Grosser*}

\section{Suma}

Los días no contaban para mí, bastaba la palabra.

Yo escuchaba en cuclillas cómo alguna palabra conversaba con otra.

No contaban los días.

Pero extravié palabras y los días me siguieron con sus largos abrigos.

Yo iba mirando el suelo.

"Ése no cuenta el cuento", vaticinaron unos. Yo no escuchaba a nadie, yo contaba con ellas. Los días fueron como trapos mojados en los pies. Habité días feroces porque perdí palabras. Eran contadas y eran, al fin, las que contaban. El tiempo es implacable.

El que pierde palabras tiene los días contados.

Jorge Boccanera ${ }^{1}$

El propósito de esta exposición es dar a conocer mis experiencias de investigación y trabajo de campo en el estudio de dos idiomas: el tének, de la Huasteca potosina, y el ngigua, de la Mixteca alta oaxaqueña. A lo largo de más de dos décadas de trabajo he intentado establecer las di-

* Dirección de Lingüística, INAH. ${ }^{1}$ Sordomuda, EDUCA, 1991. versas causas y consecuencias de la conservación o el desplazamiento del uso de la lengua indígena en una y otra comunidad, así como las diferentes actividades y actitudes de los hablantes y sus cuadros intelectuales al respecto. Pero mis reflexiones no pretenden ser exhaustivas ni agotar el análisis de una problemática extremadamente compleja. 


\section{Importancia de las condiciones específicas}

El desarrollo de las luchas por el reconocimiento de los derechos y las culturas de los pueblos indígenas y su carácter contradictorio con la internacionalización capitalista de la sociedad y la economía mundial, cuyas expresiones más notorias en nuestra área fueron los procesos revolucionarios centroamericanos en el pasado reciente y el movimiento zapatista mexicano durante los últimos años, situaron el tema en un primer plano de la actualidad política y social.

Ello no ha sido hasta hoy suficiente para superar los discursos y enfoques generalizadores sobre las variadas problemáticas y situaciones de las diversas comunidades, sustentados en la idea simplificadora de que la consideración de sus rasgos comunes haría superfluo ocuparse de las condiciones específicas que se dan en cada una de ellas. En este tratamiento esquematizante de la cuestión indígena continúan incurriendo tanto gobernantes como funcionarios, políticos y periodistas, e incluso no pocos expertos en antropología y otras ciencias sociales. Basten para confirmarlo el articulado y los fundamentos de la reciente ley sobre los derechos y las culturas indígenas sancionada por el Congreso mexica- no, así como la mayor parte de los proyectos y las intervenciones durante el debate nacional que se desarrolló en torno al tema.

Mi experiencia en la investigación de dos lenguas en distinto grado de su proceso de extinción confirma que tanto las circunstancias prevalecientes como las perspectivas de su modificación y la actitud de los agentes en juego difieren de modo notable según los casos y aconsejan estrategias y tratamientos disímiles por parte de sus protagonistas.

El tének, también llamado huasteco, y el ngigua, conocido como chocholteco, perteneciente el primero a la familia mayance y el segundo al grupo otomangue, están al borde de la desaparición, pese a los esfuerzos por reactivarlos de un reducido sector de sus hablantes y de algunas instituciones indigenistas.

Sin embargo, su destino inmediato podría diferir como consecuencia de los distintos escenarios que presenta la lucha por su revitalización.

En ello incide y tendrá consecuencias probablemente distintas no sólo el número y las características de sus hablantes y de sus emergentes élites de intelectuales orgánicos sino también la forma en que dichas lenguas se transmiten y se relacionan con las nuevas generaciones, así como las posibilidades ofrecidas por el contex- 
NOTAS

to socioeconómico en que se hallan inmersos.

La piedra de toque de su posible supervivencia será, en ambos casos, no su rescate, registro y conservación como testimonio lingüístico sino su refuncionalización social. Porque las lenguas, que son transmisoras de las diversas culturas, se extinguen cuando sus principales funciones -expresión, comunicación- han sido progresivamente reemplazadas por la lengua dominante, en nuestro caso el castellano. Pero en realidad las que son dominantes o dominadas no son simple y exclusivamente las lenguas ni las culturas en sí, sino que las situaciones por las que éstas atraviesan son la expresión de las relaciones de poder a nivel de la estructura social.

\section{Lengua, identidad y autonomía}

En cuanto al tema de mi especialidad $y$, en particular, al alcance y al futuro de las lenguas que investigo, es preciso señalar ante todo que resulta muy difícil e incierto determinar con precisión el número de hablantes de una lengua indígena. En primer lugar, debido a las limitaciones del criterio con que se realizan los censos; en segundo, a causa de que muchas personas niegan hablar su lengua in- dígena materna por considerarlo, con razón o sin ella, un factor de discriminación. En cuanto a los censos, no existe un criterio riguroso -ni aun entre los lingüistas- acerca de qué se entiende por 'hablar una lengua'. Las definiciones van desde poder decir o entender unas cuantas palabras hasta tener un amplio dominio de sus aspectos creativos, tanto en lo gramatical como en lo comunicacional. En los censos, la principal variable de ponderación, hasta el extremo de ser considerado el rasgo cultural más importante, es el uso o no de la lengua indígena. A mi juicio, este criterio es discutible o, al menos, sintetizable con otras consideraciones tanto o más esenciales. Podría relatar innumerables anécdotas de personas que se consideran indígenas aunque no hablen ni entiendan la lengua de sus antepasados, y de otras que, dominándola, no son ni se sienten indígenas. En una alta proporción de casos existe una ancha franja gris que hace que la calidad de indígena se trate, en definitiva, de una cuestión relativamente subjetiva.

Si antes del 'tropezón de Colón'² en lo que hoy es territorio mexicano se hablaban más de 124 idiomas, ¿por qué hoy sólo se hablan unas 56

${ }^{2}$ Expresivo comentario de mi maestro Leonardo Manrique Castañeda acerca del llamado 'encuentro de dos mundos' o ‘descubrimiento de América’. 
o 62 lenguas, según los diversos criterios de clasificación? ¿Por qué las otras se han extinguido? Una posible interpretación es que los pueblos que hoy conservan el uso de su lengua materna poseían, además de condiciones históricas y socioeconómicas propicias, una voluntad más firme de asumir el derecho a la existencia y de poner en juego los medios para defender ese derecho, ya sea de modo deliberado o implícitamente. Su historia conocida, si es que la hay, es la historia de su sometimiento, escrita por los vencedores. Pero si lo que se entiende por marginalidad es la no participación de los indígenas en la estructura económica, política y educativa, la carencia de servicios, las diferencias culturales, el desempleo, la falta de dominio del idioma oficial, entre otras características, recordemos que la fuerza de trabajo indígena es la que produce la mayor parte de los alimentos que consumimos en los centros urbanos, la que construye puentes y carreteras, la que conforma una considerable proporción de la base de masas en la estructura política nacional a través de diversas organizaciones indigenistas, campesinas, sociales y partidarias. La verdadera marginalidad es el despojo de tierras, la insalubridad, la desnutrición, la mortalidad infantil, el analfabetismo. De ahí que en muchos casos haya que leer las de- mandas de autonomía indígena no sólo como un reclamo de autogobierno sino también, a la vez, como una exigencia de integración al conjunto nacional.

\section{Estructura social y supervivencia lingüística}

Ciertas idealizaciones de tendencia indigenista conciben a los pueblos indígenas como estructuras socioeconómicas homogéneas. Pero en el seno de estos pueblos se reproducen algunas de las relaciones de intercambio desigual que caracterizan a la sociedad nacional en su conjunto, articuladas con otras desigualdades más remotas. Por eso es que, al plantearme el interrogante acerca de las causas por las cuales algunos pueblos ostentan una tradición escrita y el uso de su lengua como un orgullo cultural mientras otros no, me formulo la siguiente reflexión: en los grupos indígenas actualmente más diferenciados o estratificados en lo social y económico se dan -dentro del contexto del desarrollo capitalista- las condiciones para el surgimiento de una burguesía local, es decir, de indígenas propietarios de parcelas más extensas que requieren de la fuerza de trabajo de otros indígenas para levantar la cosecha y, en general, para las labores agrícolas. Se trata, en tér- 
NOTAS

minos económicos, de un proceso capitalista de acumulación primaria.

En tales contextos se da una división social del trabajo que favorece el surgimiento de un sector intelectual en condiciones de reflexionar sobre su propia realidad. Ahora bien, ¿por qué en algunos grupos indígenas emerge una burguesía y en otros no? Una explicación posible reside en las condiciones naturales del desarrollo económico desigual en cada región: donde el clima, la calidad del suelo y por consiguiente la abundancia de recursos naturales permite la producción de excedentes para su venta o intercambio en los mercados nacional e internacional, se dan las premisas favorables para la acumulación primaria; si dichas condiciones están ausentes observamos grupos humanos en pobreza extrema.

Pero también es necesario considerar que si se integra a esta reflexión el criterio histórico, ${ }^{3}$ aparece con evidencia que las macroetnias (nahuas, zapotecos, mixtecos, mayas, así como quechuas y aymaras en otras latitudes) son las herederas de civilizaciones que tuvieron en su pasado precolombino dos experiencias comunes fundamentales estrecha-

${ }^{3}$ Véase Stefano Varese, “¿Estrategia étnica o estrategia de clase?”, en Indianidad y descolonización en América Latina, 1979, México, Nueva Imagen, p. 363 y ss. mente vinculadas entre sí: 1) la presencia de una estructura social de clases y, por lo tanto, 2) la existencia de un aparato estatal con distintos grados de organización, cobertura y refinamiento administrativo, según los momentos y las zonas. Además, todas estas macroetnias se constituyeron como civilizaciones fundamentalmente agrarias, y es en el proceso de estructuración y reestructuración colonial que se las confinó como campesinado integrante de una formación económica que los engloba. En dichas comunidades existían élites dirigentes, intelectuales tradicionales, capas medias, trabajadores y otros pueblos tributarios, etc. Lo que importa destacar es que, en el caso de las macroetnias, el período colonial y el desarrollo capitalista de las nuevas naciones independientes han producido una estratificación de clases en la cual son claramente identificables, por lo menos: un sector social mayoritario conformado por un campesinado de pequeños propietarios; ${ }^{4}$ una pequeña burguesía incipiente de comerciantes, maestros artesanos y especialistas independientes y, finalmente, una burguesía media que, según los distintos casos, puede ser de origen antiguo, consolidada alrededor de la monopoliza-

${ }^{4}$ Desde el punto de vista de la conciencia social importa relativamente poco el tamaño de sus parcelas. 
ción de la tierra o, tal vez, reciente y apoyada económicamente sobre el control de las actividades terciarias comerciales y de transporte, o bien ligada a las diversas burocracias del aparato estatal.

\section{Los contrastes: el caso del ngigua}

Entre los chocholtecos, la estratificación social presenta un carácter poco consolidado o se encuentra apenas perfilada o en surgimiento. En la zona que me tocó trabajar más del $90 \%$ de la superficie de la tierra no es adecuada para la agricultura, pues está situada en una región montañosa con profundas barrancas o de monte alto; una pequeña parte es de temporal y una ínfima de riego. A esto hay que agregarle erosión, deforestación, heladas, sequías y granizadas, propias de su clima semiárido. Las principales actividades económicas son la cría de chivos, borregos y aves de corral, así como la agricultura de autoconsumo (trigo, maíz, frijol, haba, calabacita y algunos árboles frutales como durazno y capulín), además del pequeño comercio (principalmente para la venta de refrescos embotellados, cerveza y mezcal) y el tejido y la venta de sombreros de palma o de fibra sintética.
Si establecemos tres franjas generacionales se observa que en la generación intermedia, de los 25 a los 45 años, algunos sólo hablan el idioma de sus antepasados y un alto porcentaje no lo habla, aunque algunos lo entienden. Los menores de 25 años no lo hablan ni lo entienden. Sólo unos cuantos ancianos conservan una conciencia de la ruptura cultural que representa la atrofia del uso de la lengua; se convierten en 'recordantes', en testigos de su pasado aunque hayan perdido la función de transmisores plenos de un universo colectivo. La ausencia de destinatarios -niños y jóvenes que entendieran o hablaran el ngigua- produjo una falta de la memoria aunada a una baja autoestima de su lengua y de su cultura. No hay contextos de uso, por lo que los ancianos se convierten en protagonistas y autores de su propia conciencia cultural. Dentro de la zona chocholteca, en las escuelas del sistema educativo indígena ya no se enseña la lengua a los niños, quienes tampoco reciben ese legado por parte de su madre. Apenas en los últimos años surgió el interés por implementar programas de lectoescritura en chocholteco por parte de algunos maestros pertenecientes a instituciones gubernamentales, como la Dirección general de culturas populares con sede en Huajuapan de León y el Centro coordinador indigenista, 
dependencia del Instituto nacional indigenista con oficinas en Nochixtlán. Pero hasta ahora los resultados han sido bastante precarios, debido a la escasa preparación de los instructores, al desinterés de los niños y a la alta fragmentación dialectal que se aprecia en la región, resultado precisamente del avanzado grado de extinción en que se halla la lengua y que dificulta la estandarización de un alfabeto.

A principios de 1990 los chocholtecos obtuvieron una hora diaria de transmisión a través de 'La voz de la Mixteca', con sede en Tlaxiaco, Oaxaca, una de las 27 radioemisoras bilingües auspiciadas por el Instituto Nacional Indigenista (INI), profundamente arraigadas en centenares de comunidades indígenas. Esa radio transmitía hasta entonces programas bilingües español-mixteco y españoltriqui. La inclusión de un espacio dirigido a los chocholtecos, al promover el uso de la lengua oral, generó un verdadero renacimiento del interés de niños y jóvenes por sus raíces culturales. En diciembre de 1991 este proyecto obtuvo incluso el apoyo de recursos económicos por parte de los Fondos de Solidaridad para la Promoción del Patrimonio Cultural de los Pueblos Indígenas de México, que entregó el gobierno federal a través del INI. Pero hacia mediados de 1996 tales programas bilingües en español y ngigua se habían interrumpido por diversos problemas prácticos -carencia de recursos técnicos, económicos y humanos-, aunque sigue habiendo intenciones de reanudarlos. Sin embargo, es preciso estar conscientes de que emisiones radiofónicas como éstas, programas de enseñanza de la lengua o eventuales publicaciones impresas con apoyo del Instituto Lingüístico de Verano (ILV), no son suficientes por sí solas para salvar un idioma cuya subsistencia depende sustancialmente de la recuperación de todas sus principales funciones vitales. Factores decisivos a este respecto resultan, naturalmente, el contexto socioeconómico nacional y mundial.

\section{Los signos vitales del tének}

Distinto es el panorama que pude observar en la Huasteca potosina. En la cabecera distrital, Tancanhuitz de Santos, funciona una Unidad de Radio Bilingüe español-tének desde hace más de veinte años, además de espacios de una hora que se transmiten los domingos por tres emisoras comerciales: una de Ciudad Valles, otra de San Luis Potosí, y una de Tampico, estado de Tamaulipas. En 1983 se invitó a los niños de la región a que escribieran cuentos y leyendas para motivarlos a utilizar 
y desarrollar su dominio de la lengua tének. Se recibieron 19 relatos, pese a que no se ofreció otro estímulo que la satisfacción de escucharlos por la radio. Con el tiempo se consideró que esas narraciones también podían ser útiles para apoyar la enseñanza de la lectura y la escritura en lengua tének en las escuelas del sistema educativo bilingüe.

Hasta no hace muchos años, la escuela rural se había convertido en una experiencia ingrata y hasta cruel para el alumno indígena, porque lo incapacitaba para ejercer su derecho a la lengua materna y no le aportaba siquiera conocimientos plenos en la lengua nacional. El uso de su propia lengua por parte de los alumnos indígenas llegó a ser penado con castigos corporales en los años 40 del siglo veinte, época de la llamada 'alfabetización directa' o ‘integracionista'. Afortunadamente, los tiempos parecen estar cambiando de modo favorable y los nuevos intelectuales orgánicos de las diversas comunidades tének han tomado en sus manos la tarea de que su población se apropie del lenguaje como una herramienta para expresar sus ideas $\mathrm{y}$ sentimientos, buscando a la vez la armonía, la belleza, la cadencia y el ritmo de las palabras adecuadas. No sin vencer enormes dificultades de toda índole, y gracias a su perseverancia y suma de esfuerzos y voluntades, un grupo de maestros organizados en el Comité de Desarrollo Cultural de la Etnia Tének publicó en 1999 un diccionario escolar con más de dos mil entradas. Pero además los tének lograron poner en práctica por primera vez una política de autogestión, ya que muchos de los gastos que se originaron fueron $\mathrm{cu}-$ biertos por los propios participantes, mediante aportaciones voluntarias o bien organizando eventos y actividades para recaudar fondos y financiar de ese modo el proyecto.

En la Huasteca potosina la mayoría de las mujeres y los niños son monolingües en tének y los hombres son bilingües incipientes y apenas pueden producir enunciados significativos en español. Además, en razón de que 'ya se acabó la tierra por repartir’, los hijos más jóvenes de muchas familias emigran, ya sea en busca de fuentes de trabajo o porque encuentran condiciones favorables para proseguir sus estudios.

Estos jóvenes son los que han ido adquiriendo cada vez mayor peso social y conforman la nueva intelectualidad indígena. Son los maestros preparados en las escuelas misioneras católicas o evangélicas o en otras instituciones análogas, así como en diversos organismos y grupos indigenistas; son los técnicos agropecuarios, los licenciados, los pocos afortunados que llegan a obtener una 
NOTAS

carrera universitaria completa, que concluyen el ciclo medio o que terminan carreras de especialización no universitarias. Son los hijos de familias cuyos padres gozan de una situación económica más desahogada, y por lo tanto pueden contratar peones y prescindir de la ayuda de los niños en las labores agrícolas o domésticas. Es así como lo superestructural o ideológico se revierte sobre el plano estructural y manifiesta sus efectos en lo que se refiere a la valoración positiva de la lengua y la cultura propias.

En la Huasteca potosina es evidente que la presión que ejerce el sistema educativo y los valores del conjunto de la sociedad nacional han generado una especie de resistencia pasiva, puesto que se han ido adoptando sólo algunos de los elementos lingüísticos y culturales del mundo hispanohablante; este proceso permite por el momento mantener vigentes algunos de los principales rasgos de identidad del grupo, preservando sobre todo los ámbitos doméstico y comunitario, con el que la escuela y otros factores mantienen sólo una relación tangencial.

\section{Lengua y cultura}

No es lo mismo ser una persona letrada y educada que ser una persona culta, es decir, insertada orgánicamente en la propia cultura. La primera puede ser instruida sin reconocer sus raíces históricas, sin estar vinculada ni solidarizada con los principios que rigen la vida y las esperanzas de los otros miembros de su comunidad. Alguien que ha pasado por el proceso de educación formal puede ser totalmente aculturado, puede haber perdido toda capacidad de situarse frente a su pasado colectivo, de asumirlo como propio, de comprender el proyecto implícito o explícito de su pueblo, de compartir críticamente el conjunto de conocimientos y valores históricamente acumulados por sus mayores.

Mientras el tema indígena se considere como un 'problema' y se trate indiscriminadamente, en bloque, como un bulto que estorba y del que hay que desprenderse lo antes posible y de cualquier modo, no se van a resolver los conflictos principales ni los derivados. Esto tiene que ver tanto con los planes que se apliquen en las diversas comunidades como con el papel que se le asigne o que asuman sus élites intelectuales.

Conservar una lengua no es una reivindicación más entre muchas otras que se pueden plantear, sino que hace a la esencia misma de la identidad cultural.

Al decir del poeta Juan Gelman "cada lengua es una cosmovisión he- 
redada, construida por generaciones y generaciones de hablantes, y lo que cada palabra en una lengua arrastra, calla y dice y vuelve a callar, está unido a una constelación de silencios y decires de todas las palabras de una lengua”.

De ahí que la conservación del idioma propio equivalga a preservar las posibilidades de desarrollo de un pensamiento y una concepción del mundo enraizada en la historia, las tradiciones y las costumbres de cada comunidad. Nada menos que eso es lo que está en juego en las realidades sociolingüísticas que acabamos de analizar.

El poeta siciliano Ignazio Buttita lo dijo así:

Mete a todo un pueblo en la cantina, desnúdalo,

despójalo, tápale la boca, y sigue siendo todavía libre.

Quítale el trabajo, el pasaporte,

la mesa donde come, la casa donde duerme, y es aún rico.

Un pueblo se vuelve pobre y esclavo cuando le roban la lengua recibida de sus padres y está perdido para siempre. Se vuelve pobre y esclavo cuando las palabras no paren palabras y se comen entre sí. 